\title{
Preparation and Characterization of PVDF/g- C3N4/chitosan Nanocomposite Membrane for the Removal of Direct Blue 14 Dye
}

\section{Parya Hasanzade}

Islamic Azad University Ahar Branch

Parvin Gharbani (D parvingharbani@yahoo.com )

Islamic Azad University Ahar Branch https://orcid.org/0000-0003-1763-4993

\section{Fahime Derakhshan}

Islamic Azad University Ahar Branch

Behnaz Memar Maher

Islamic Azad University Ahar Branch

\section{Research Article}

Keywords: Membrane, PVDF/g-C3N4/Chitosan, Chitosan, Direct Blue 14

Posted Date: February 19th, 2021

DOl: https://doi.org/10.21203/rs.3.rs-218812/v1

License: (a) (i) This work is licensed under a Creative Commons Attribution 4.0 International License.

Read Full License

Version of Record: A version of this preprint was published at Journal of Polymers and the Environment on April 12th, 2021. See the published version at https://doi.org/10.1007/s10924-021-02145-y. 


\title{
Preparation and characterization of PVDF/g- $\mathrm{C}_{3} \mathrm{~N}_{4} / \mathrm{Chitosan}$ nanocomposite membrane for the removal of
}

\section{Direct Blue 14 dye}

Parya Hasanzade $^{1}$, Parvin Gharbani $^{2}{ }_{\text {口, Fahime Derakhshan fard }}^{1}$, Behnaz Memar Maher $^{1}$

${ }^{1}$ Department of Chemical Engineering, Ahar Branch, Islamic Azad University, Ahar, Iran

${ }^{2}$ Department Chemistry, Ahar Branch, Islamic Azad University, Ahar, Iran

\begin{abstract}
Polyvinylidene fluoride (PVDF)/g- $\mathrm{C}_{3} \mathrm{~N}_{4} /$ Chitosan thin film membranes were prepared for removal of Direct Blue 14 dye (an anionic dye) from aqueous solutions. PVDF/g-C3N4/Chitosan membranes were prepared by immersing of PVDF/g-C3N4 membrane in solution containing various concentrations of chitosan. The resulting membranes were characterized by XRD, FESEM, TEM and AFM. Also, pure water flux, salt rejection, water content, antifouling properties of prepared membranes were investigated. The resulting demonstrate that pure water flux was decreased by increasing of chitosan concentration, while water content, antifouling properties and salt rejection were increased. It is found that chitosan has major impact on the membrane structural properties due to transform of the PVDF membrane into hydrophilic ones. It is reported that maximum 93\% rejection of Direct Blue 14 was obtained by $\mathrm{PVDF} / \mathrm{g}-\mathrm{C}_{3} \mathrm{~N}_{4} / \mathrm{Chitosan}$ membrane. Compared to the PVDF/g-C3N4 membrane, the experimental results showed that PVDF/g-C3N4/Chitosan membranes demonstrated high potential mainly due to greater hydrophilicity and further minimizing membrane fouling.
\end{abstract}

Keywords: Membrane; PVDF/g-C3N4/Chitosan; Chitosan; Direct Blue 14

Corresponding Author: Department of chemistry, Ahar Branch, Islamic Azad University, Ahar, Iran (Parvin Gharbani), E-mail: parvingharbani@yahoo.com; p-gharabani@iau-ahar.ac.ir 


\section{Introduction}

Dyes are one of the most important and destructive pollutants that are used in various industries such as textile, paper, etc. Discharge of effluent containing these pollutants into the water endangers human health due to its toxicity and mutagenicity, and in some cases cause genetic mutation [1]. Various methods have been used to remove dyes such as adsorption, photocatalysis, chemical oxidation, coagulation, chemical precipitation, and membrane systems. Membrane technology is considered as one of the effective methods in removing pollutants due to its high separation performance, easy application, low energy consumption, environmentally friendly and lack of production of secondary pollutants [2]. Today, polymers have been widely used to produce membrane. However, intrinsic hydrophobicity of some of polymers generated a lot of problems such as fouling of membrane which leads to pure water flux decline and decrease life time of membrane. membrane processes based on the pressure driving force can be classified in 4 categories: Microfiltration (MF), Ultrafiltratin (UF), Nanofiltration [NF] and Reverse Osmosis (RO)[3]. A large percentage of used synthetic membranes in industries are polymeric. The reason is simplicity of their construction, cheapness and processability. In addition, in recent years, the use of copolymers and mixtures of polymers have led to the expansion of the range of polymeric membranes [4]. Among the polymer membranes, Polyvinylidene Fluoride (PVDF) membrane has grown significantly. PVDF is a polymeric material that has been considered by many researchers due to outstanding properties such as mechanical strength, stability and high chemical resistance compared to other common polymeric materials. These polymers are as a semi-crystalline polymer which crystalline phase of them provides thermal stability and their amorphous phase generate optimal flexibility of membranes [5]. The reported life time of PVDF membranes in conventional processes is about 3-5 years and in water treatment processes is 5-10 years [6]. PVDF membranes are widely used in filtration of containments. However, they usually suffer from membrane fouling due to their hydrophobic property [7]. Generally, the performance of a membrane changes over time and the flux of the membrane gradually decreases, which is due to the two factors; concentration polarization and fouling of the membrane [8]. Fouling of membrane is a complex physicochemical phenomenon that usually occurs due to deposition and adsorption of fouling agents on the outer surface of the membrane as well as the inner surface of the cavities [9] so, the flux decreases at constant operating pressure. Therefore, it is necessary to increase the operating pressure in order to keep constant the flux, which this issue increases the energy cost. As regards the most important advantage of membrane processes is the low operating costs, so the capability of membrane processes is challenging any factor that conflicts with this advantage. As a result, fouling is considered as the most important challenge in the membrane industry and the main barrier in its development related to the liquid phase [10]. Hence, many efforts 
have been made to prevent fouling problems. Fouling of membrane depends severely on the to the extent of hydrophilicity, the size of the cavities and morphology of membrane[11]. In fact, hydrophobic membranes suffer to fouling more than hydrophilic membranes. At present, modifying membrane has considered as an efficient technology to overcome these problems. Modification of polymeric membranes takes place using of surface coatings, surface bonding, plasma process, blending with suitable polymers as well as the use of nanoparticles[1213] such as $\mathrm{SiO}_{2}$ [14], $\mathrm{Al}_{2} \mathrm{O}_{3}$ [15], $\mathrm{ZrO}_{2}$ [16],clay[17], $\mathrm{ZnO}$ [18], $\mathrm{TiO}_{2}$ [19]. The aim of surface modification is to create new hydrophilic groups on the membrane surface [12], that will lead to increase membrane hydrophilicity and enhanced antifouling properties of membrane [13].

Recently, carbon materials such as $\mathrm{g}-\mathrm{C}_{3} \mathrm{~N}_{4}$ have been considered in membrane production process due to their simplicity, low production cost and high chemical stability [20]. $\mathrm{g}-\mathrm{C}_{3} \mathrm{~N}_{4}$ is a one of the carbon nitride compounds in which carbon and nitrogen atoms are joined together by n-conjugated bonds and form tri-s-triazine structural units [21]. Up to now, there have been several reports on the synthesis and application of the PVDF/g-C3N4 membrane and results revealed that dispersion of $\mathrm{g}-\mathrm{C}_{3} \mathrm{~N}_{4}$ in PVDF leads to enhanced of strength and thermal stability of the membrane (due to physical and chemical interactions between PVDF and functional groups at the surface of $\mathrm{g}-\mathrm{C}_{3} \mathrm{~N} 4$ ) [22-23]. But did not affect hydrophilic or antifouling properties of PVDF.

Chitosan is used as a polymeric solution to modify the surface of the membrane and also simultaneously improving the anti-fouling and hydrophilicity properties. Chitosan is known as a hydrophilic, inexpensive, non-toxic, biodegradable and antibacterial agent that contains a large number of reactive and active hydroxyl and amine groups that can influence the electrochemical properties of cation exchange by increasing the interaction of ions with the membrane surface and improve the electric field around the membrane [10]. Chitosan also is used in the coating layer on hydrophobic membranes, micro-cavity membranes and drug delivery due to the unique properties such as selectivity, high reactivity and good structural strength[24].

The aim of this study is surface modification of polyvinylidene fluoride (PVDF)/ graphitic carbon nitride (gC3N4) membrane with different quantities of chitosan by dip coating method. Synthesized membranes were characterized by XRD, FESEM, EDS mapping, AFM and TEM. The filtration properties of membranes were characterized by water flux, porosity, average pore radius, water content, antifouling and rejection of Direct Blue14 (DB14) dye [Fig. 1]. The experiments were conducted in the dead-end filtration mode. 


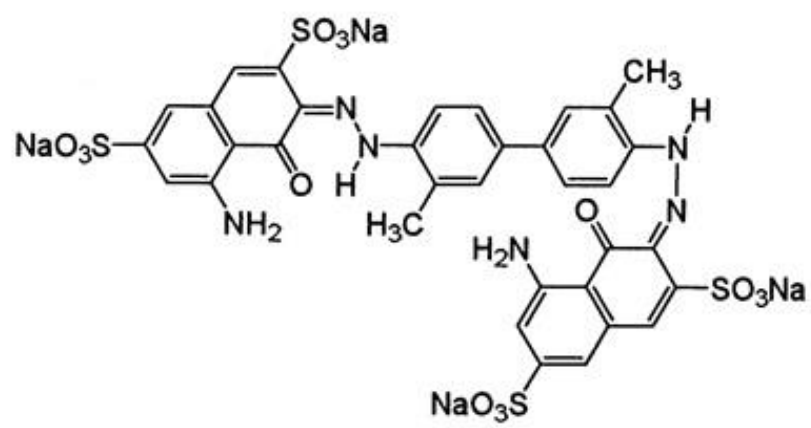

Fig. 1: Structure of Direct Blue 14

\section{Materials and Methods}

\section{Materials}

Melamine, Dimethylformamide (DMF), Chitosan, $\mathrm{NaCl}$, Acetone and Acetic acid were purchased from Merck company. Polyvinylidene fluoride (PVDF) and Direct Blue 14 dye were prepared from Sigma-Aldrich.

Synthesis of polymeric substrate

To prepare of polymeric substrate, firstly $0.7 \mathrm{~g}$ of PVDF was dissolved in $5 \mathrm{~mL}$ DMF and $5 \mathrm{~mL}$ acetone at 40$40^{\circ} \mathrm{C}$ for $1 \mathrm{hr}$. Then $0.15 \mathrm{~g}$ of g-C3N4 (synthesized by Condensation Polymerization) [25] was added into dissolved PVDF and was stirred at $50{ }^{\circ} \mathrm{C}$ for one hour followed by sonication for $2 \mathrm{hr}$ to remove air bubbles. Using dissolution casting method, $10 \mathrm{~mL}$ of solution was slightly transferred in petri dish to achieve a uniform thick layer. After evaporation of solvents ( $24 \mathrm{hr}$ at room temperature), prepared membranes were removed by sharp blades and the thickness of membranes was measured (Table 1).

Decoration of Chitosan on polymeric substrate

To prepare of different chitosan solutions, $2 \%, 3 \%$ and $4 \%$ of chitosan was dissolved in $1 \%$ acetic acid solution and the mixture was kept under stirring at $70 \mathrm{C}^{\circ}$ for $6 \mathrm{hr}$ to obtain a homogeneous solution. Then, PVDF/g-C3N4 films was immersed in chitosan solution for $2 \mathrm{hr}$ to deposition of chitosan onto films. They were left to dry for 24hr at room temperature. The prepared membranes were named as PVDF, PC (PVDF and g-C3N4), PCC1 (PVDF/g-C3N4-chitosan 2\% w/v), PCC2 (PVDF/g-C3N4-chitosan 3\% w/v) and PCC3 (PVDF/g-C3N4-chitosan $4 \% \mathrm{w} / \mathrm{v})$.

Membrane Characterization 
Porosity ( $\varepsilon$ ) of membranes was calculated using gravimetric method from Eq. (1) [26]:

$\varepsilon=\frac{\left(\mathrm{W}_{\mathrm{W}}-\mathrm{W}_{\mathrm{d}}\right)}{\mathrm{A} \times \mathrm{L} \times \rho_{\mathrm{W}}} \times 100$

where, $W_{w}, W_{d}, \rho_{w}, A$ and $L$ are wet and dry weight $(\mathrm{kg})$ of membrane, density of water $\left(998 \mathrm{~kg} / \mathrm{m}^{3}\right)$, effective surface area of membrane $\left(\mathrm{m}^{2}\right)$ and thickness of membrane $(\mathrm{m})$, respectively. All experiments were performed in triplicate. Also, average pore radius of membrane $(\mathrm{nm})$ were calculated using Guerout-Elford-Ferry (GEF) Equation (2): [27]

$r_{m}=\sqrt{\frac{8 \eta L Q(2.9-1.75 \varepsilon)}{\varepsilon A \Delta P}}$

Where, $\eta, \mathrm{L}, \mathrm{Q}, \mathrm{A}, \varepsilon$ and $\Delta \mathrm{P}$ are viscosity of water $\left(8.9 \times 10^{-4} \mathrm{~Pa} . \mathrm{s}\right)$, thickness of membrane $(\mathrm{m})$, volume of permeated pure water per unit time $\left(\mathrm{m}^{3} / \mathrm{s}\right)$, surface area of membrane $\left(\mathrm{m}^{2}\right)$, porosity and operational pressure $(\mathrm{Pa})$, respectively.

Mean roughness

AFM images were used to characterize of membrane surface morphology and to estimate the surface roughness of membranes. Mean roughness (Ra) Eq. (3) and root mean square (RMS) Eq. (4) were obtained from AFM analysis.

$\mathrm{Ra}=\left[\frac{1}{\operatorname{LxLy}} \int_{0}^{\mathrm{Lx}} \int_{0}^{\mathrm{Ly}}[\mathcal{F}(\mathrm{x}, \mathrm{y}) \mathrm{dxdy}]\right]$

$\mathrm{RMS}=\left[\left(\frac{1}{\mathrm{Ae}}\right) \int_{0}^{\mathrm{Lx}} \int_{0}^{\mathrm{Ly}} \mathrm{Z}^{2}(\mathrm{x}, \mathrm{y}) \mathrm{dxdy}\right]$

\subsection{Water content}

Water content of prepared membranes were evaluated by soaking of membranes into deionized water for $24 \mathrm{~h}$ and then weighted. Water content of prepared membrane was calculated from difference between wet and dry weight of membranes (Eq. 5):

Water content $=\left\lfloor\frac{\mathrm{W}_{\mathrm{wet}}-\mathrm{W}_{\mathrm{dry}}}{\mathrm{W}_{\mathrm{dry}}}\right\rfloor \times 100$

Three samples were tested, and average value was reported. 
Filtration experiments

A dead-end filtration cell with an effective area of $7.06 \mathrm{~cm}^{2}$ was used to evaluate the performance of the prepared membranes. Firstly, membranes were pre-pressurized at 1.5 bar for $60 \mathrm{~min}$, then the pressure was reduced to 1 bar for $15 \mathrm{~min}$.

Pure water flux

Pure water flux ( $\left.\mathrm{J}_{0}\right)$ was measured at 1 bar for $15 \mathrm{~min}$ and was calculated from Eq. (6).

$\mathrm{J}_{0}=\frac{\mathrm{M}(\mathrm{t})}{\mathrm{A} \Delta \mathrm{t}}$

$\mathrm{J}(\mathrm{t}), \mathrm{M}(\mathrm{t}), \Delta \mathrm{t}$ and $\mathrm{A}$ are pure water flux $\left(\mathrm{kg} / \mathrm{m}^{2} \mathrm{~h}\right)$, permeated water weight $(\mathrm{kg})$, time of filtration $(\mathrm{h})$ and effective surface area of membrane $\left(\mathrm{m}^{2}\right)$, respectively.

Dye removal

Efficiency of prepared membranes was probed by \% rejection $(\mathrm{R})$ of Direct Blue14 dye and was calculated from Eq. (7) using UV-Vis spectrophotometer.

$R(\%)=\left(1-\frac{A_{\text {petmeate }}}{A_{\text {feed }}}\right) \times 100$

Where, $\mathrm{A}_{\text {petmeate }}$ and $\mathrm{A}_{\text {feed }}$ are absorption of DB14 in permeate and feed solutions, respectively.

Fouling experiment

In order to study of anti-fouling performance of prepared membranes, DB14 solution (2 mg/L) was used as a foulant using the dead-end filtration cell $\left(\mathrm{J}_{1}\right)$. Then, the membranes were washed by deionized water and the pure water flux $\left(\mathrm{J}_{2}\right)$ were conducted. $\mathrm{J}_{1}$ and $\mathrm{J}_{2}$ were calculated using Eq. 6. The membranes antifouling ability were evaluated by Total Fouling Ratio (TFR), Reversible Fouling Ratio (RFR), Irreversible Fouling Ratio (IFR) and Flux Recovery Ratio) FFR) using Eqs. (8-11) [28], respectively:

$$
\begin{aligned}
& \mathrm{TFR}=\left(\frac{\mathrm{J}_{0}-\mathrm{J}_{1}}{\mathrm{~J}_{0}}\right) \times 100 \\
& \mathrm{RFR}=\left(\frac{\mathrm{J}_{2}-\mathrm{J}_{1}}{\mathrm{~J}_{0}}\right) \times 100 \\
& \mathrm{IFR}=\left(\frac{\mathrm{J}_{0}-\mathrm{J}_{2}}{\mathrm{~J}_{0}}\right) \times 100 \\
& \% \mathrm{FRR}=\left(\frac{\mathrm{J}_{2}}{\mathrm{~J}_{0}}\right) \times 100
\end{aligned}
$$


Analysis

The prepared membranes were analyzed by FTIR (Spectrum Two FT-IR Spectrometer of PerkinElmer company), XRD (Malvern Panalytical's X-ray diffractometers), FESEM, EDX, Dot mapping (ZEISS SIGMA VP FESEM of Germany equipped EDS and Mapping detector of Oxford Instruments of England, AFM (Nanosurf Mobile S of Switzerland) and TEM (Zeiss-EM10C-100 KV of Germany) instruments. The contact angle of membranes was measured by Contact angle measuring system model OCA 15 plus. The Direct Blue 14 dye concentration was recorded with UV-Vis spectrophotometer (DR5000-15V (HACH CO, America).

\section{Results and discussion}

FTIR of chitosan and g-C3N4 are shown in Fig. 2a. The chitosan has a strong peak at 2900- $3700 \mathrm{~cm}^{-1}$, which corresponds to the symmetric stretching vibration of $\mathrm{O}-\mathrm{H}$ and $\mathrm{N}-\mathrm{H}$, which indicates the presence of intramolecular hydrogen bonds [29]. A peak at $2898 \mathrm{~cm}-1$ can be attributed to $\mathrm{C}-\mathrm{H}$ asymmetric stretching. An appeared peak at $1612 \mathrm{~cm}^{-1}$ is confirmed the presence of residual $\mathrm{N}$-acetyl group $(\mathrm{C}=\mathrm{O}$ stretching of amide $\mathrm{I}) . \mathrm{CH}_{3}$ symmetrical deformation and C-O stretching vibration peaks of chitosan are also seen in 1395 and $1060 \mathrm{~cm}^{-1}$, respectively [30]. In the FTIR spectrum of $\mathrm{g}-\mathrm{C}_{3} \mathrm{~N}_{4}$, the broad peak at $3000-3500 \mathrm{~cm}^{-1}$ is corresponded to the $\mathrm{N}-\mathrm{H}$ starching vibration modes due to incomplete condensation of amine group and also appeared peaks at 1622, 1411 and 1236 $\mathrm{cm}^{-1}\left(1200\right.$ to $\left.1700 \mathrm{~cm}^{-1}\right)$ are attributed to the stretching vibration modes of $\mathrm{CN}$ heterocycles[29]. XRD analysis was used to study the crystallography of membranes. XRD patterns of Chitosan, g-C3N4, PVDF, PVDF/g-C3N4 and PVDF/g- $\mathrm{C}_{3} \mathrm{~N}_{4} /$ Chitosan membranes are shown in Fig. 2b. XRD peak of amorphous structures of chitosan is shown at $2 \theta=20.19^{\circ}$, respectively [31]. In the XRD pattern of $g-\mathrm{C}_{3} \mathrm{~N}_{4}$, the peaks observed at $2 \theta=13.04^{\circ}$ and $27.53^{\circ}$ correspond to the s-triazine units and the conjugated aromatic groups of the $\mathrm{g}-\mathrm{C}_{3} \mathrm{~N}_{4}$ layers that are indexed to the (100) and (002) planes of the hexagonal g- $\mathrm{C}_{3} \mathrm{~N}_{4}$ [JCPDS 34-0061], respectively [25]. In the XRD pattern of prepared PVDF membrane, a clear peak at $2 \theta=20.35^{\circ}$ and 3 weak peaks are appeared at $2 \theta=18.3^{\circ}, 26.9^{\circ}$, $39.3^{\circ}$. The peaks obtained at $2 \theta=18.3^{\circ}, 20.35^{\circ}, 26.9^{\circ}$ and $39.3^{\circ}$ correspond to (002), (021), (100) and (020) planes confirms of the monoclinic $\alpha$ - phase crystal of PVDF [32]. 
(a)

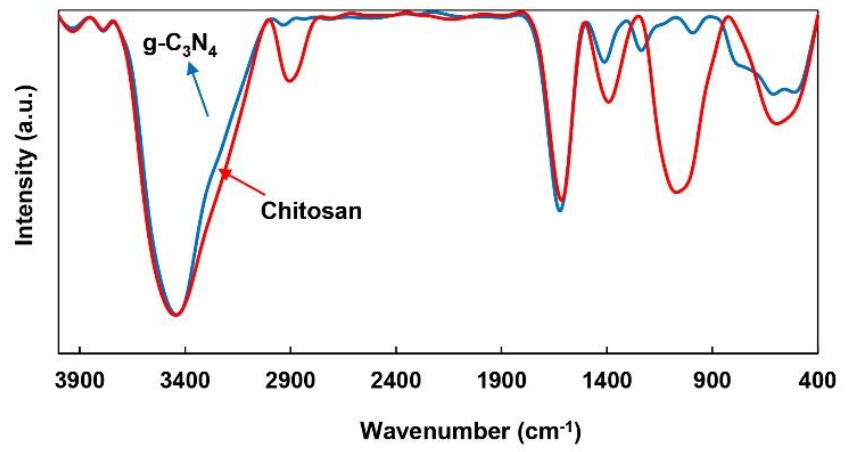

(b)

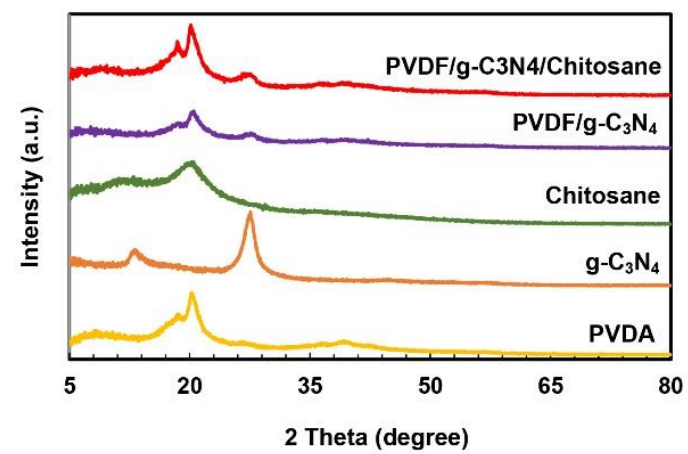

Fig 2. a) FTIR and b)XRD analysis

The resulting peaks at $2 \theta=20.35$ and $27^{\circ}$ of PVDF/g- $\mathrm{C}_{3} \mathrm{~N}_{4}$ membrane are corresponded to PVDF and $\mathrm{g}-\mathrm{C}_{3} \mathrm{~N}_{4}$, respectively. Both PVDF and g- $\mathrm{C}_{3} \mathrm{~N}_{4}$ spectra are seen in the PVDF/g- $\mathrm{C}_{3} \mathrm{~N}_{4} /$ Chitosan membrane. The peaks appearing at $2 \theta=18.53,20.16^{\circ}$ are related to PVDF and at $2 \theta=27.4^{\circ}$ is corresponded to g-C3N4. As known, chitosan has a peak at $2 \theta=20.18^{\circ}$. So, increment of peak intensity in the XRD of the PVDF/g- $\mathrm{C}_{3} \mathrm{~N}_{4} / \mathrm{Chitosan}$ membrane $\left(2 \theta=20^{\circ}\right)$ can be attributed to chitosan.

FESEM images of surface and cross section of prepared membranes are shown in Fig. 3. FESEM of PVDF (Fig. 3a) displays that prepared PVDF membrane has a cavity-like structure while it was expected to have a denser structure. It may be due to the fact that only PVDF with a relative humidity of $0 \%$ has a dense structure, while an increase of the moisture content gives the PVDF membrane a cavity-like and porous structure. The prepared membrane has a DMF that evaporates faster than water. Water vapor (ambient air) is completely dissolved in DMF and penetrates the membrane by the diffusion process and leads to phase separation. Phase separation takes place because water is not solvent of PVDF [33]. Compared to PVDF membrane, the prepared PVDF/g- $\mathrm{C}_{3} \mathrm{~N}_{4}$ membrane (Fig. 3b) is denser relatively and its cavity size is smaller due to the placement of $\mathrm{g}-\mathrm{C}_{3} \mathrm{~N}_{4}$ particles in PVDF cavities. Deposition of chitosan on PVDF/g- $\mathrm{C}_{3} \mathrm{~N}_{4}$ membrane (Fig. 3c) also showed that the porous structure of the membrane was significantly reduced and indicates the formation of a uniform Chitosan film on the PVDF / $\mathrm{g}-\mathrm{C}_{3} \mathrm{~N}_{4}$ membrane. A comparison of Figs $3 \mathrm{~b}$ and $3 \mathrm{c}$ confirms that the surface and cavities of the PVDF/ $\mathrm{g}-\mathrm{C}_{3} \mathrm{~N}_{4}$ membrane have been covered with Chitosan. 


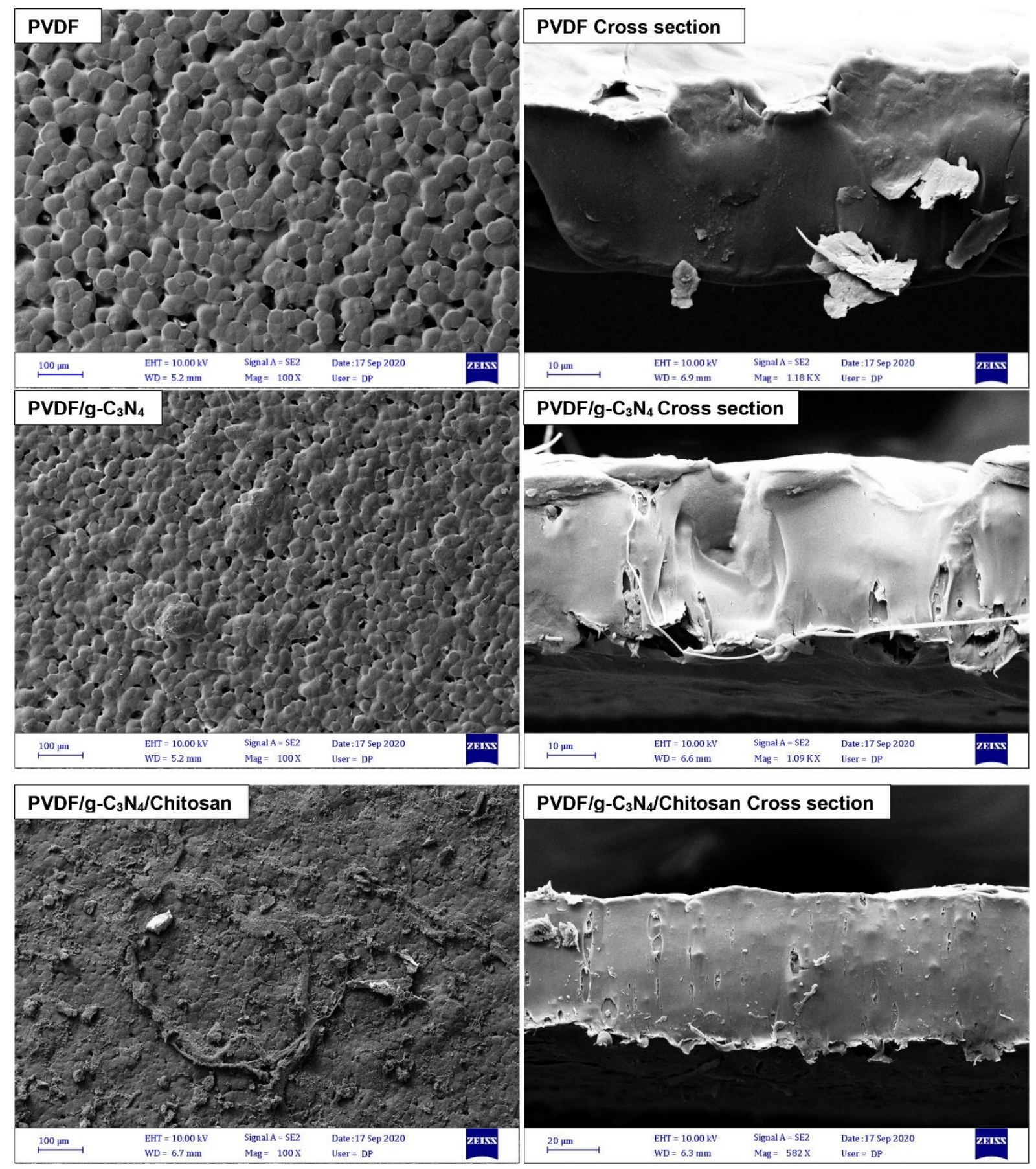

Fig 3. FESEM images of prepared membranes, surface morphology and cross section

EDS was used to analysis of all elements on the membrane surface and results is demonstrated the surface of membrane consists of $52.6 \% \mathrm{~F}, 43.75 \mathrm{C}, 2.4 \% \mathrm{O}$ and $1.3 \% \mathrm{~N}$ (not shown here). EDS mapping and TEM image of PVDF/g-C3N4/Chitosan membrane are shown in Fig 4. EDS mapping is clearly confirmed the modification of PVDF/g-C3N4 by chitosan. TEM image (Fig. 3e) of PVDF/g-C3N4/Chitosan membrane demonstrated chitosan is dispersed on $\mathrm{PVDF} / \mathrm{g}-\mathrm{C}_{3} \mathrm{~N}_{4}$ membrane with an average size of $30 \mathrm{~nm}$ and spherically, which has 
dramatically improved the hydrophilicity of the membrane. The results show that the PVDF / g- $\mathrm{C}_{3} \mathrm{~N}_{4} / \mathrm{Chitosan}$ composite membrane not only retains its organic properties but also improves its hydrophilicity and anti-fouling properties.
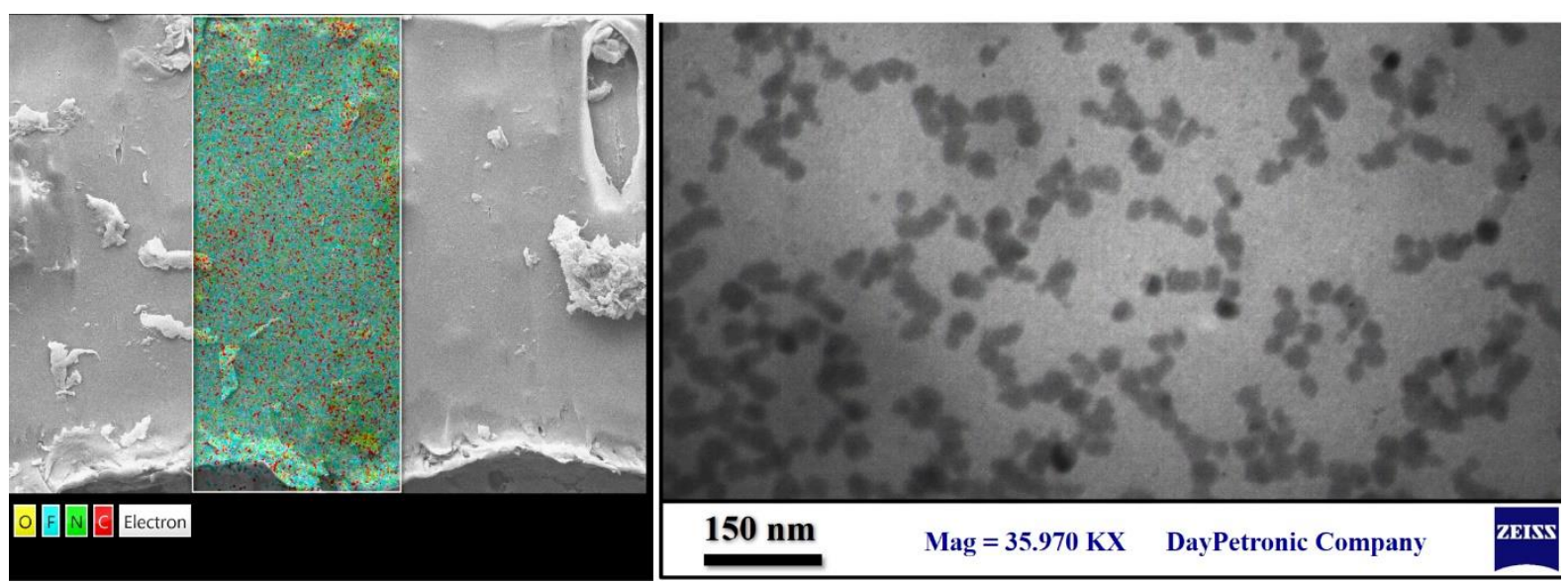

Fig 4. TEM and EDS mapping of PVDF/g-C3N4/Chitosan membrane

The surface roughness of a layer is affected by the wetting property of the membrane, which is obtained by measuring the contact angle [34]. Evaluation of contact angle is simple way to collect the information about hydrophilicity or hydrophobicity of membrane surface and low value of contact angle shows the hydrophilicity of membrane. The contact angle of the outer surface of the prepared membranes is measured before and after the coating (Fig. 5). The maximum contact angle is obtained for PVDF membrane $\left(93.41^{\circ}\right)$ due to the hydrophobicity nature. Addition of $\mathrm{g}-\mathrm{C}_{3} \mathrm{~N}_{4}$ to PVDF did not affect significantly on the contact angle $\left(90.00^{\circ}\right)$ While the contact angle is reduced to $36.61^{\circ}$ with the deposition of chitosan on the surface of PVDF/g- ${ }_{3} \mathrm{~N}_{4}$ membrane. It can be concluded, the deposition of chitosan on the surface of PVDF $/ g-\mathrm{C}_{3} \mathrm{~N}_{4}$ membrane, significantly reduced contact angle. So, an important factor that increases the hydrophilicity of PVDF membranes is the presence of chitosan on the outer surface of the membrane. This means that adding chitosan to the membrane surface, hydrophilizes the membrane and increases the hydrophilicity, which is effective in reducing the contact angle. Membrane hydrophilicity helps it to react better with electrolytes [34]. In fact, the hydrophilicity improvement of the chitosan-modified membrane can be related to the hydroxyl active groups in the chitosan polymer [29]. In general, the wettability property, or in other words, the hydrophilicity of the membrane surface will be improved by reducing the contact angle of water. 

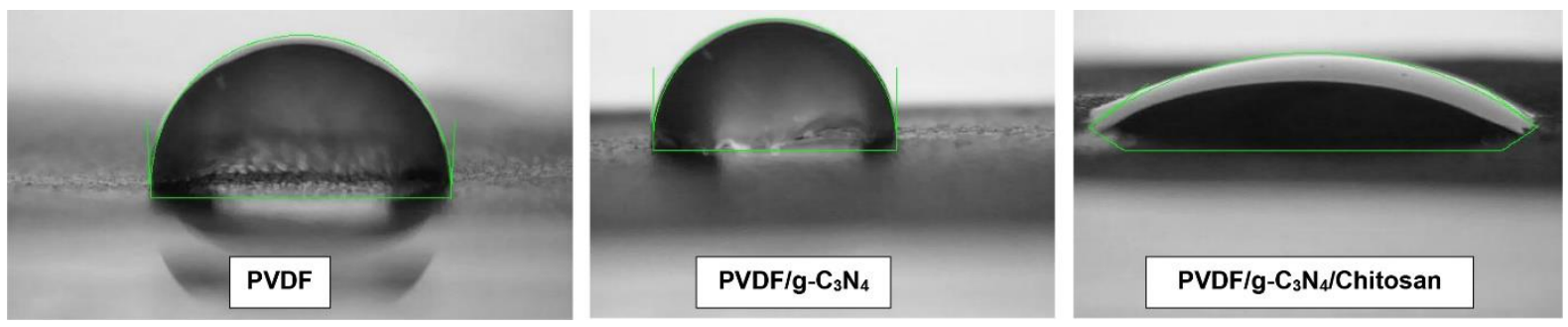

Fig 5. Water contact angle of prepared membranes

The $\%$ porosity and mean pore radius of prepared membranes are presented in Table 1 . The effects of the g-C $3 \mathrm{~N} 4$ and chitosan content on porosity and mean pore radius of PVDF membrane proved that both of porosity and mean pore radius were decreased with addition of g-C3N4 and chitosan. The porosity and mean pore radius of PVDF membrane was $93.43 \%$ and $11.98 \mathrm{~nm}$, respectively. By addition pf g-C3N4 (PC membrane), they were reached to $97.07 \%$ and $9.87 \mathrm{~nm}$. While, by addition of $4 \%$ chitosan, the porosity and mean pore radius of membrane was decreased to $81.12 \%$ and $5.54 \mathrm{~nm}$, respectively. Filling of PVDF/g-C3N4 membrane pores by chitosan results smoother surface and due to reduction of mean pore radius.

Mean roughness $(\mathrm{Ra})$ and root mean square average (RMS) of prepared membranes are presented in Table 1. As shown, the value of Ra for PVDF, PVDF/g- $\mathrm{C}_{3} \mathrm{~N}_{4}$ and PVDF/g-C3N4/Chitosan membranes are decreased as 26.51, 9.50, $8.30 \mathrm{~nm}$, respectively. Also, RSM for PVDF (32.21nm), PVDF/g- $\mathrm{C}_{3} \mathrm{~N}_{4}(12.93 \mathrm{~nm})$ and PVDF/g$\mathrm{C}_{3} \mathrm{~N}_{4} /$ Chitosan(11.13nm) was calculated.

Table 1. Thickness, mean pore radius, porosity, mean roughness and RMS of membranes

\begin{tabular}{|c|c|c|c|c|c|}
\hline membrane & $\begin{array}{l}\text { Thickness (m } \\
\mathrm{m})\end{array}$ & $\begin{array}{l}\text { Mean pore radius } \\
(\mathrm{nm})\end{array}$ & Porosity (\%) & $\begin{array}{l}\text { Mean roughness } \\
\mathrm{Ra}(\mathrm{nm})\end{array}$ & RMS \\
\hline PVDF & 0.03 & 11.98 & 93.43 & 26.51 & 32.21 \\
\hline $\mathrm{PC}$ & 0.1 & 9.87 & 97.07 & 9.50 & 12.93 \\
\hline PCC1 & 0.16 & 7.87 & 90.31 & 8.30 & 11.13 \\
\hline PCC2 & 0.2 & 6.1 & 90.19 & ----- & ----- \\
\hline PCC3 & 0.23 & 5.54 & 81.12 & ----- & ----- \\
\hline
\end{tabular}

AFM images of prepared membranes are presented in Fig. 6 and confirms the reduction of roughness and content angle. As seen, PVDF membrane have many porous and rougher structures that induced peak and valley structure 
like. Addition of chitosan and g-C3N4 to PVDF is diminished the pores of membrane, so a smoother surface is resulted that lead to decease of Ra and RMS from 26.51 to $8.30 \mathrm{~nm}$ and 32.21 to $11.13 \mathrm{~nm}$, respectively.

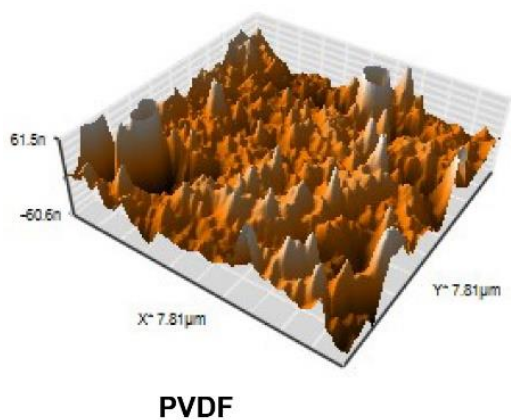

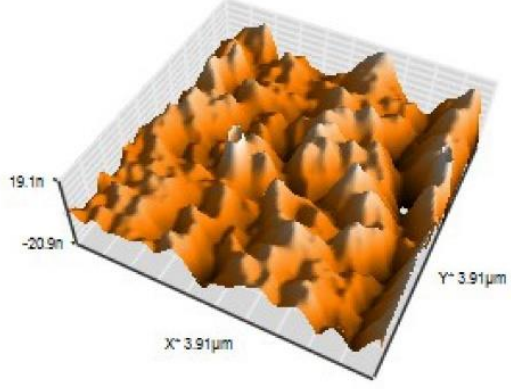

PVDF/g- $\mathrm{C}_{3} \mathrm{~N}_{4}$

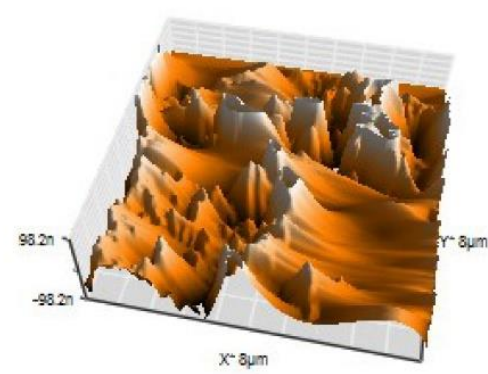

PVDF/g- $\mathrm{C}_{3} \mathrm{~N}_{4} /$ Chitosan

Fig 6. AFM images of PVDF, PVDF/g-C3N4 and PVDF/g-C3N4/Chitosan membranes

Pure water flux

Results of pure water flux from prepared membranes is shown in Fig. 7. As can be seen, the pure water flux in $\mathrm{PVDF} / \mathrm{g}-\mathrm{C}_{3} \mathrm{~N}_{4} / \mathrm{Chitosan}$ and PVDF/g-C3N4 membranes is less than pure PVDF, which indicates the formation of a compact layer on the PVDF substrate that prevents the passage of water molecules. These results agree with the results of the FESEM image, which shows that the PVDF membrane is the most permeable. In fact, chitosan due to its high molecular weight, can easily suspend more g-C3N4 aggregates [35]. As a result, it will reduce the surface of the membrane and reduce the size of cavities. As seen, the maximum permeability for membranes with $2 \%$ chitosan (PCC-1) is about $49.87 \%$, while with increasing the \%weight of chitosan to (PCC-3) 4 , a significant decrease in flux $(14.76 \%)$ is observed.

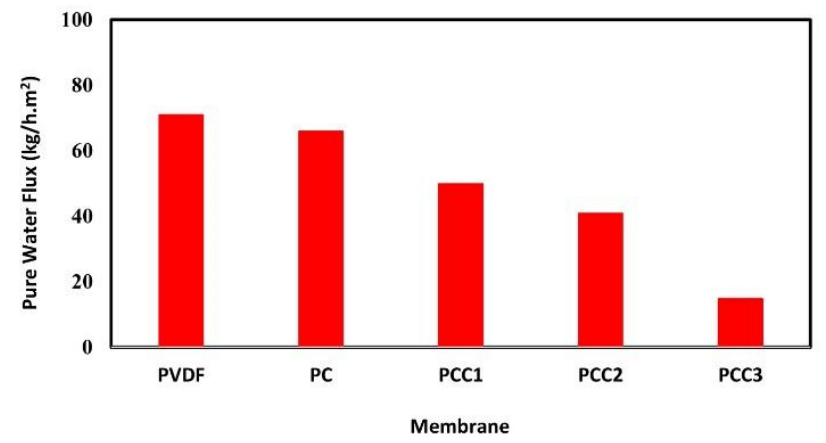

Fig 7. Pure water flux of PVDF, PC, PCC1, PCC2 and PCC3 membranes 


\section{Water content}

Water content Results of prepared membrane is presented in Fig. 8. As can be seen, the water content in PVDF/g$\mathrm{C}_{3} \mathrm{~N}_{4}$ /Chitosan membranes increased compared to PVDF / g- $\mathrm{C}_{3} \mathrm{~N}_{4}$ and PVDF membranes. As we know, both PVDF and $\mathrm{C}_{3} \mathrm{~N}_{4}$ are hydrophobic in nature while chitosan is hydrophilic. Therefore, in the presence of chitosan when the membranes are immersed in water for a long time, the amount of absorbed water increases in the cavities and the structure of the membrane, so water content increases. The trapping water in the PVDF and PVDF / g$\mathrm{C}_{3} \mathrm{~N}_{4}$ membranes is due to water trapping in the cavities, while the water content in the PVDF / g- $\mathrm{C}_{3} \mathrm{~N}_{4} / \mathrm{Chitosan}$ membranes is not only due to the water trapping in the cavities but also due to the high hydrophilic nature of the water. The results of the contact angle verified this statement. Comparison of the prepared membranes with different percentage of chitosan also confirms that the water content of the membranes has increased with increasing the percentage of chitosan in the membrane. In fact, surface modification with chitosan increases membrane permeability and decreases membrane resistance which is due to changes in the hydrophilicity of the membrane.

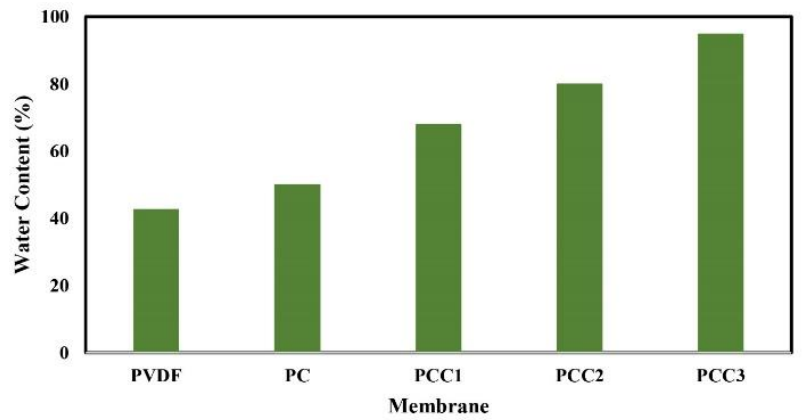

Fig. 8. Water content results of PVDF, PC, PCC1, PCC2 and PCC3 membranes

\section{Salt Rejection}

Removal and rejection of ions is related to the porous structure and the charged surface of the membrane. Treatment of prepared membranes was performed with $\mathrm{NaCl}$ electrolyte with a concentration of $3.28 \%$ w/v at 1 bar at $20{ }^{\circ} \mathrm{C}$. Results of $\%$ rejection of salt by membranes has been shown in Fig. 9. Based on these results, the chitosan deposition on the membrane has clearly increased the ability to rejection of $\mathrm{NaCl}$ from PVDF to PVDF / g- $\mathrm{C}_{3} \mathrm{~N}_{4}$ / Chitosan membrane. The reason for this sharp increase can be due to the adsorption ability of chitosan and cover the cavities with chitosan polymer on the surface of the membrane. As known, the efficiency of a membrane does not depend only on the size distribution of the cavity but also depends more on the electrostatic 
repulsion of soluble ions in the feed and the charge on the surface of the membrane. The presence of active hydroxyl groups on the chitosan surface can enhance the electrostatic adsorption of sodium ions with positive charge. Similarly, the repulsion interaction between the membrane surface and chlorine ions with a negative charge will also be intensified at the presence of active hydroxyl groups [36]. Therefore, it can be concluded the presence of chitosan polymer significantly increases the amount of salt adsorption and consequently of salt rejection.

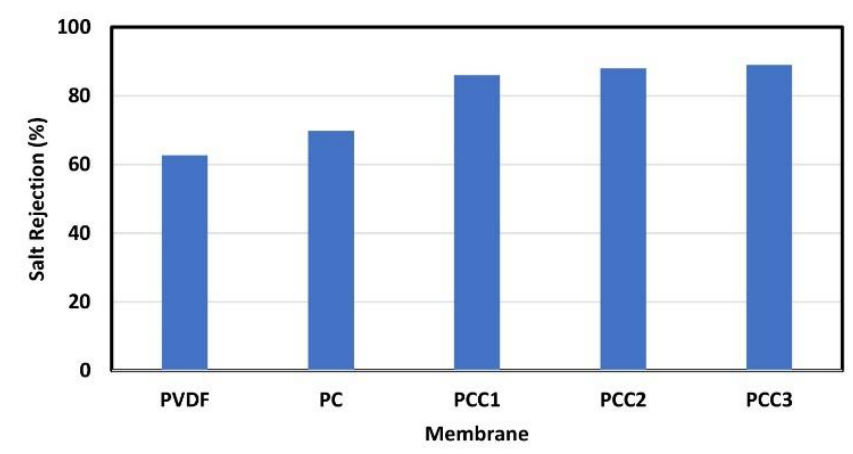

Fig. 9. Salt rejection of PVDF, PC, PCC1,PCC2 and PCC membranes

The mechanical strength of the fabricated membranes showed the membrane strength increased with increasing g- $\mathrm{C}_{3} \mathrm{~N}_{4}$ and chitosan. The enhancement of membrane strength indicated good adhesion between PVDF, g- $\mathrm{C}_{3} \mathrm{~N}_{4}$ and chitosan particles. The reason of the increase in mechanical properties may be due to the good dispersion of g- $\mathrm{C}_{3} \mathrm{~N}_{4}$ and the interaction between $\mathrm{g}-\mathrm{C}_{3} \mathrm{~N}_{4}$ and chitosan. $\mathrm{g}-\mathrm{C} 3 \mathrm{~N} 4$ is hydrophobic and insoluble in water and has many hydrophilic groups such as $-\mathrm{NH}$, which help to dissolve it in water. Chitosan is also a hydrophilic biopolymer with two active groups $-\mathrm{NH}_{2}$ and $-\mathrm{OH}$, so a strong hydrogen bond is formed between chitosan and g$\mathrm{C}_{3} \mathrm{~N}_{4}$. The reaction between $\mathrm{g}-\mathrm{C}_{3} \mathrm{~N}_{4}$ and chitosan results in both better distribution and good adhesion of contour, which improves the mechanical properties of the membranes [35]. KIM et al. reported good adhesion of the polymer matrix and mineral filler particles increased the Young's modulus and increased the strength length [37].

Antifouling property of membranes

During the separation process due to the accumulation of the material on the cavities and the surface of the membranes, we are faced with fouling phenomena and flux reduction as a result Van der Waals bonding, hydrogen bonding and electrostatic interactions. As a result, the life of the membranes is reduced, and their function is 
impaired. The fouling problem is partially solved by increasing the hydrophilicity of the membrane surface or modifying its surface [38]. Dead end system and DB14 as foulant were used to evaluate the antifouling property of membranes. In this study, chitosan was used to increase surface hydrophilicity and reduce the fouling of membrane. The parameters of membrane fouling including TFR, RFR and IFR are shown in Fig.10a. The results show a decrease in TFR and IFR of membranes from PVDF to PVDF / $\mathrm{g}-\mathrm{C}_{3} \mathrm{~N}_{4} /$ Chitosan. While the RFR of membranes increased from $10.87 \%$ to $14.76 \%$ for PVDF and PVDF / g- $\mathrm{C}_{3} \mathrm{~N}_{4} /$ Chitosan membrane (4\% chitosan), respectively. It can be in results of removing the formed concentration polarization on the surface of PVDF / g$\mathrm{C}_{3} \mathrm{~N}_{4}$ / Chitosan membrane. IFR shows the nature of the membrane surface in the adsorption and retention of contaminants, so adsorption and retention of substances on the membrane surface increases with increasing of IFR. Fig. 10b shows the FRR results of PVDF / g- $\mathrm{C}_{3} \mathrm{~N}_{4} /$ Chitosan membrane in two consecutive cycles. Membranes were washed with $\mathrm{HCl}$ solution after dye separation. The results showed that FRR increases in the first and second cycles from $87.9 \%$ to $96.76 \%$ and $81.34 \%$ to $92.76 \%$ zxc, respectively. Because chitosan has a hydrophilic nature and the hydrophilicity of the membrane surface has improved by increasing it and as a result, the amount of material accumulation on the membrane surface is reduced, which indicates the high antifouling property of the membrane. In general, the high values of RFR and FRR of the membrane increase its resistance to fouling, which is due to the hydrophilicity of chitosan.
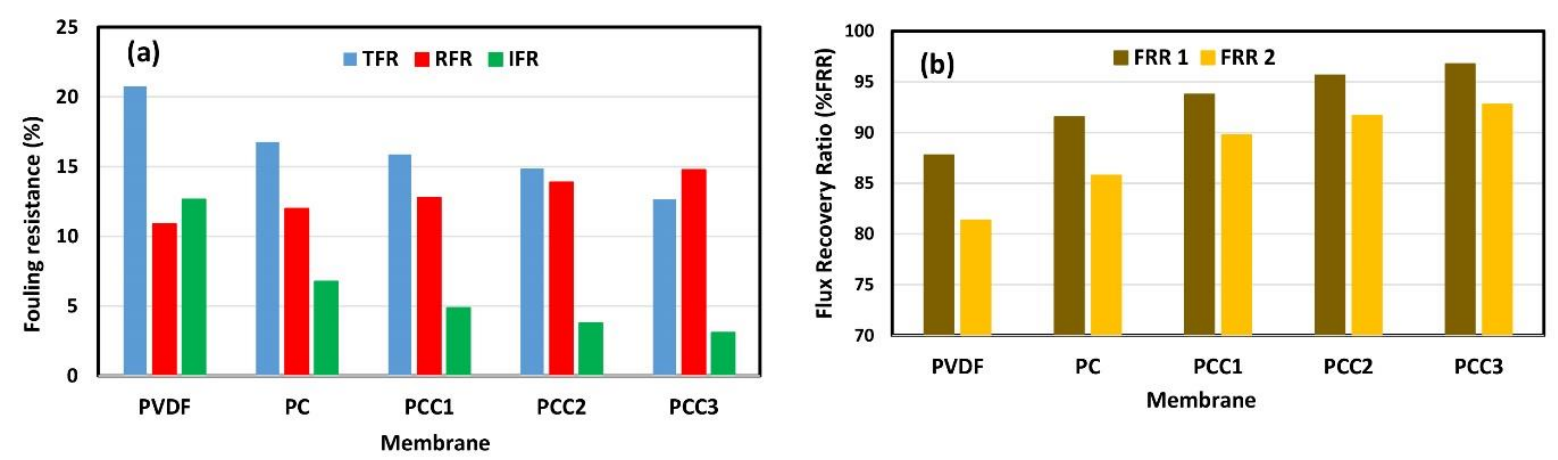

Fig 10. a) Antifouling property of membranes, b) Flux recovery ratio of membranes during 2 cycles of DB14 rejection

Dye removal efficiency of membranes

The rejection of DB14 at concentrations of $2 \mathrm{mg} / \mathrm{L}$ was performed by the prepared membranes and the results were shown in Fig.11a. According to, the percentage of rejection increased from 65.95\% for PVDF membrane to 93.15\% for PVDF / g- $\mathrm{C}_{3} \mathrm{~N}_{4} /$ Chitosan membrane. Also, the percentage of rejection of DB14 with PVDF / g- $\mathrm{C}_{3} \mathrm{~N}_{4}$ 
membrane remained almost constant $(69.98 \%)$ because the increase of $\mathrm{g}_{-} \mathrm{C}_{3} \mathrm{~N}_{4}$ on PVDF had no significantly effect on the enhancement of PVDF hydrophilicity property. It can be explained by adsorption phenomenon [22]. In fact, the efficiency of DB14\% rejection increases due to the electrostatic attraction between the negative charge of DB14 and the positive charge of chitosan on the membrane surface. Also, \% rejection of DB14 decreases with increasing the concentration of DB14 from $2 \mathrm{mg} / \mathrm{L}$ to $10 \mathrm{mg} / \mathrm{L}$ (Fig. 11b). By increase of dye concentration, contacting of dye molecules with the membrane surface is reduced and therefore due to reduction in rejection of DB14. On the other hand, saturation of active sites on the membrane could be another reason for reducing $\%$ rejection of DB14 by increase the DB14 concentration.
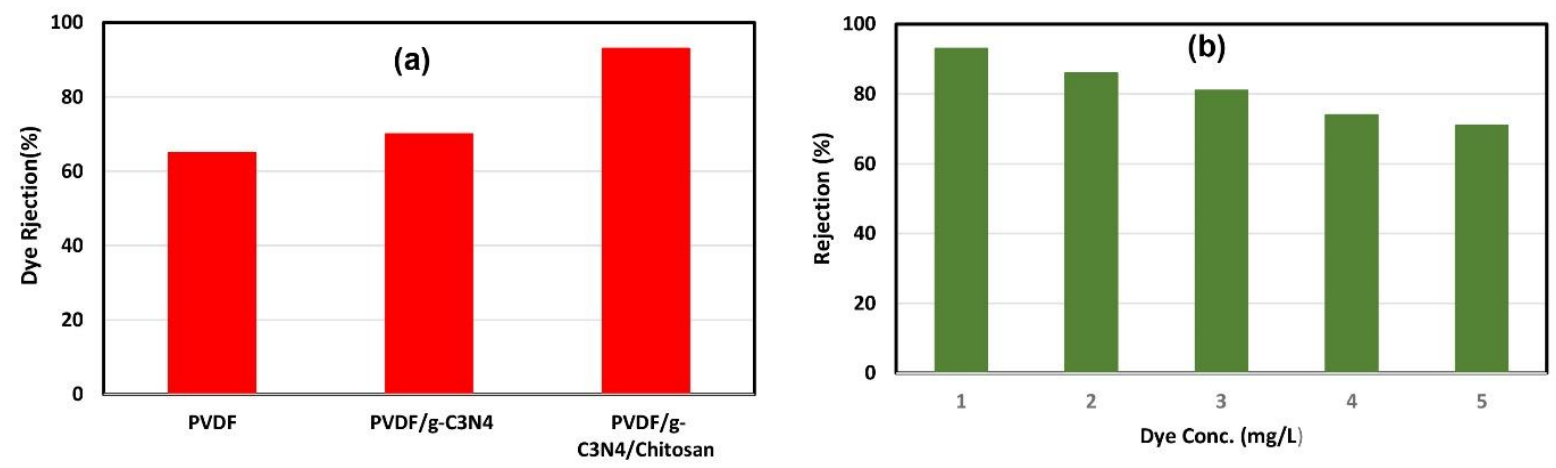

Fig 11. Rejection of DB14 (a) by prepared membranes (DB14 conc. $=2 \mathrm{mg} / \mathrm{L}$ ), b) at different concentrations by $\mathrm{PVDF} / \mathrm{g}-\mathrm{C} 3 \mathrm{~N} 4 / \mathrm{Chitosan}$ membrane

\section{Conclusion}

In this paper, PVDF, PVDF/g-C3N4 and PVDF/g-C3N4/Chitosan membranes were successfully prepared and characterized by XRD, FESEM, AFM and TEM. The pure water flux was reduced with increasing of $\%$ chitosan. Unlike, water contact, salt rejection, antifouling and mechanical properties of membrane was increased by increasing of \% chitosan. Performance of prepared membranes in terms of Direct Blue 14 rejection showed that dispersion of chitosan on top of membranes increased rejection of DB14 dye up to $94.51 \%$ using $4 \%$ chitosan.

\section{Declaration of Competing Interest}

The authors declare that they have no known competing financial interests or personal relationships that could have appeared to influence the work reported in this paper.

\section{Funding}


Not applicable.

\section{References}

[1] Zeng G, Ye Z, He Y, Yang X, Ma J, Shi H (2017) Chem Eng J 323: 572-583. https://doi.org/10.1016/j.cej.2017.04.131.

[2] Nikooe N, Saljoughi E (2017) Appl Surf Sci 413:41-49. https://doi.org/10.1016/j.apsusc.2017.04.029

[3] Cassano A, Conidi C, Ruby-Figueroa R, Castro-Muñoz R(2018) Int J Mol Sci 19: 351-372. https://doi.org/10.3390/ijms19020351

[4] Issaq H. The Book Corner: Handbook of Membrane Separations: Chemical, Pharmaceutical, Food, and Biotechnological Applications; 2009.

[5] Liu F, Hashim N.A, Liu Y, Abed M.M, Li K(2011) J Membr Sci 375(1-2):1-27. https://doi.org/10.1016/j.memsci.2011.03.014

[6]Sedaghat M, Yegani R, Jafarzadeh Y, Tavakoli A(2015) Iran J Polym Sci Technol (Persian) 28:301-311.

[7] Hamzah N, Leo C.P( 2016) Sep Purif Technol 167: 79-87. https://doi.org/10.1016/j.seppur.2016.05.005

[8] Nunes S.P, Peinemann K.V(2010) Membranes for Water Treatment, Wiley-VCH, Weinheim 11-36

[9] Balta S, Sotto A, Luis P, Benea L, Van der Bruggen B, Kim J(2012) J Membr Sci 389:155-161. https://doi:10.1016/j.memsci.2011.10.025

[10] Li N.L, Fane A.G, Ho W.S.W, and Matsuura T(2008) Advanced Membrane Technology and Applications, Wiley, New Jersey 101-104

[11] Bet-Moushoul E, Mansourpanah Y, Farhadi K, Tabatabaei M (2016)

Chem Eng J 2016; 283: 29-46. https://doi.org/10.1016/j.cej.2015.06.124

[12] Bagheripour E, Moghadassi A. R, Hosseini S.M, Van der Bruggen B, Parvizian F(2018) J Ind Eng Chem 62:311-320.https://doi.org/10.1016/j.jiec.2018.01.009

[13]Bagheripour E, Moghadassi A. R, Hosseini S.M, Ray M. B, Parvizian F, Van der Bruggen B(2018) Chem Eng Res Des 132:812-821. https://doi.org/10.1016/j.cherd.2018.02.027

[14] Cui A, Liu Z, Xiao C, and Zhang Y(2010) J Membr Sci 360:259-264. https://doi.org/10.1016/j.memsci.2010.05.023

[15]Liu F, Abed M.R.M, Li K(2011) J Membr Sci 366:97-103.https://doi.org/10.1016/j.memsci.2010.09.044 
[16] Bottino A, Capannelli G, Comite A(2002) Desalination 146:35-40. https://doi.org/10.1016/S00119164(02)00469-1

[17]Anadao P, Sato LF, Montes .R, De SantisH.S(2014) J Membr Sci 455:187-199. https://doi.org/10.1016/j.memsci.2013.12.081

[18]Jafarzadeh Y, Yegani R, Sedaghat M(2015) Chem Eng Res Des 94:417-427. https://doi.org/10.1016/j.cherd.2014.08.017

[19] Jafarzadeh Y, Yegani R(2015) Analysis of fouling mechanisms in TiO2 embedded high density polyethylene membranes for collagen separation. Chem Eng Res Des 93:684-695.

https://doi.org/10.1016/j.cherd.2014.06.001

[20]Liu Y, Yu Z, Li X, Shao L, Zeng H, J Membr Sci 617:118504-118527. https://doi.org/10.1016/j.memsci.2020.118504

[21]Inagak M, Tsumura T, Kinumoto T, Toyoda M(2019) Carbon 141:580-607. https://doi.org/10.1016/j.carbon.2018.09.082

[22]Kolesnyk I, Kujawa J, Bubela H, Konovalova V, Burban A, Cyganiuk A, Kujawski W(2020) Sep Purif Technol 117231-117244. https://doi.org/10.1016/j.seppur.2020.117231

[23]Wang H, Gong R, Qian X(2018) Membranes 8(1):14-23. https://doi.org/10.3390/membranes8010014 [24]Elizalde C.N.B, Al-Gharabli S, Kujawa J, Mavukkandy M, Hasan S.W, Arafat H.A(2018) Sep Purif Technol 190:68-76.https://doi.org/10.1016/j.seppur.2017.08.053

[25] Shekardasht M.B, Givianrad M.H, Gharbanm P, Mirjafary Z, Mehrizad A(2020) Diam Relat Mater 109:108008-108016. https://doi.org/10.1016/j.diamond.2020.108008

[26] Jia Y, Sun S, Li S, Wang Z, Wen F, Li C, Matsuyama H, Hu S(2020) Membranes 10(4):66-84. https://doi:10.3390/membranes10040066

[27] Zinadini S, Zinatizadeh A, Rahimi M, Vatanpour V, Zangeneh H, Beygzadeh M(2014) Desalination 349:145-154. https://doi.org/10.1016/j.desal.2014.07.007

[28] Wasim M, Sabir A, Shafiq M, Islam A, Azam M, Jamil T(2017) J Ind Eng Chem 50:172-182.

[29] Zhu B, Xia P, Li Y, Ho W,Yu J(2017) Appl Surf Sci 391:175-183. https://doi.org/10.1016/j.apsusc.2016.07.104

[30] Wasim M, Sagar S, Sabir A, Shafiq M, Jamil T(2017) Carbohydr Polym 174:474-483. http://dx.doi.org/10.1016/j. jiec.2017.02.011 
[31]Aswathy N.R, Palai A.K, Mohanty S, Nayak S.K(2020) Mater Lett 259:126777-126787.

https://doi.org/10.1016/j.matlet.2019.126777

[32] Li M, Katsouras I, Piliego C, Glasser G, Lieberwirth I, Blomb P. W. M, de Leeuw D. M (2013) J Mater Chem C 1:7695-7702. https://doi.org/10.1039/C3TC31774A (Paper) J.

[33] Jhaveri JH, Patel CM, Murthy ZVP (2017) J Ind Eng Chem 2017; 52:138-146,

[34]Alshahrani A.A, Algamdi M.S, Alsohaimi I.H, Nghiem L.D, Tu K.L, Al-Rawajfeh A.E, in het Panhuis M(2020) Sep Purif Technol 234:116088. https://doi.org/10.1016/j.seppur.2019.116088

[35] Vatanpour V, Madaeni S. S, Moradian R, Zinadini S, Astinchap B(2012) Sep Purif Technol 90:69-82. https://doi.org/10.1016/j.seppur.2012.02.014.

[36] Kim H, Biswas J, and Choe S(2006) Polymer 47:3981-3992. https://doi.org/10.1016/j.polymer.2006.03.068

[37]Vatanpour V, Madaeni S.S, Moradian R, Zinadini S, Astinchap B(2011) J Membr Sci 375(1-2):284-294.

[38] Liu T. Y, Bian L. X, Yuan H. G, Pang B, Lin Y. K, Tong Y( 2015) J Membr Sci 478:25-36.

https://doi.org/10.1016/j.memsci.2011.03.055 
Figures

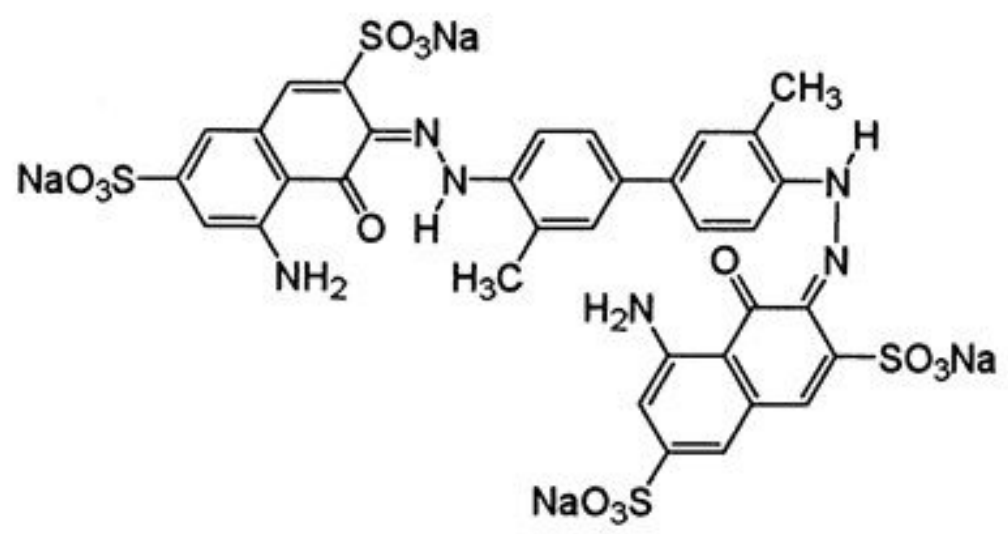

Figure 1

Structure of Direct Blue 14

(a)

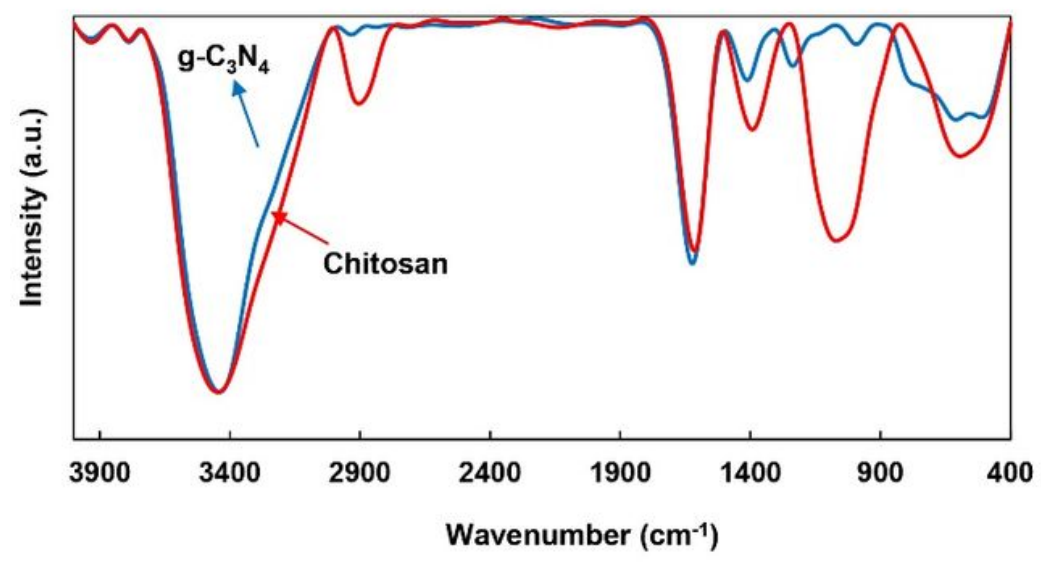

(b)

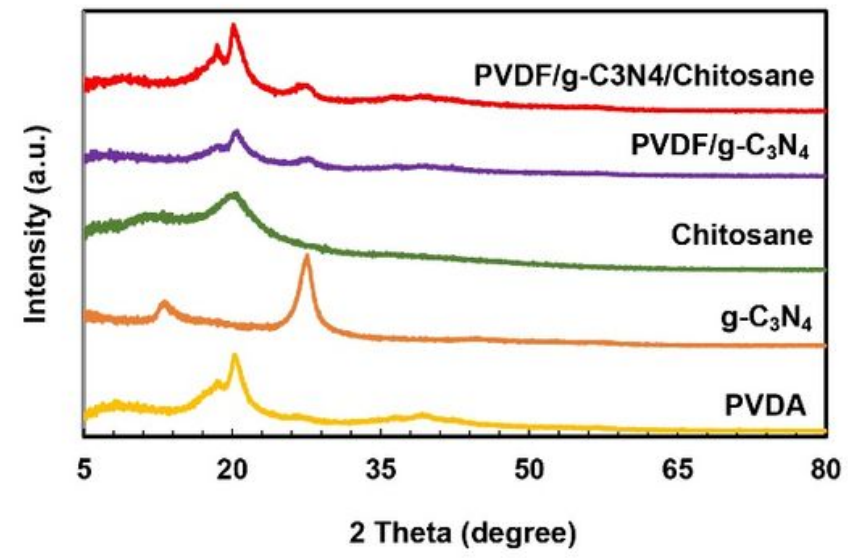

Figure 2

a) FTIR and b)XRD analysis 


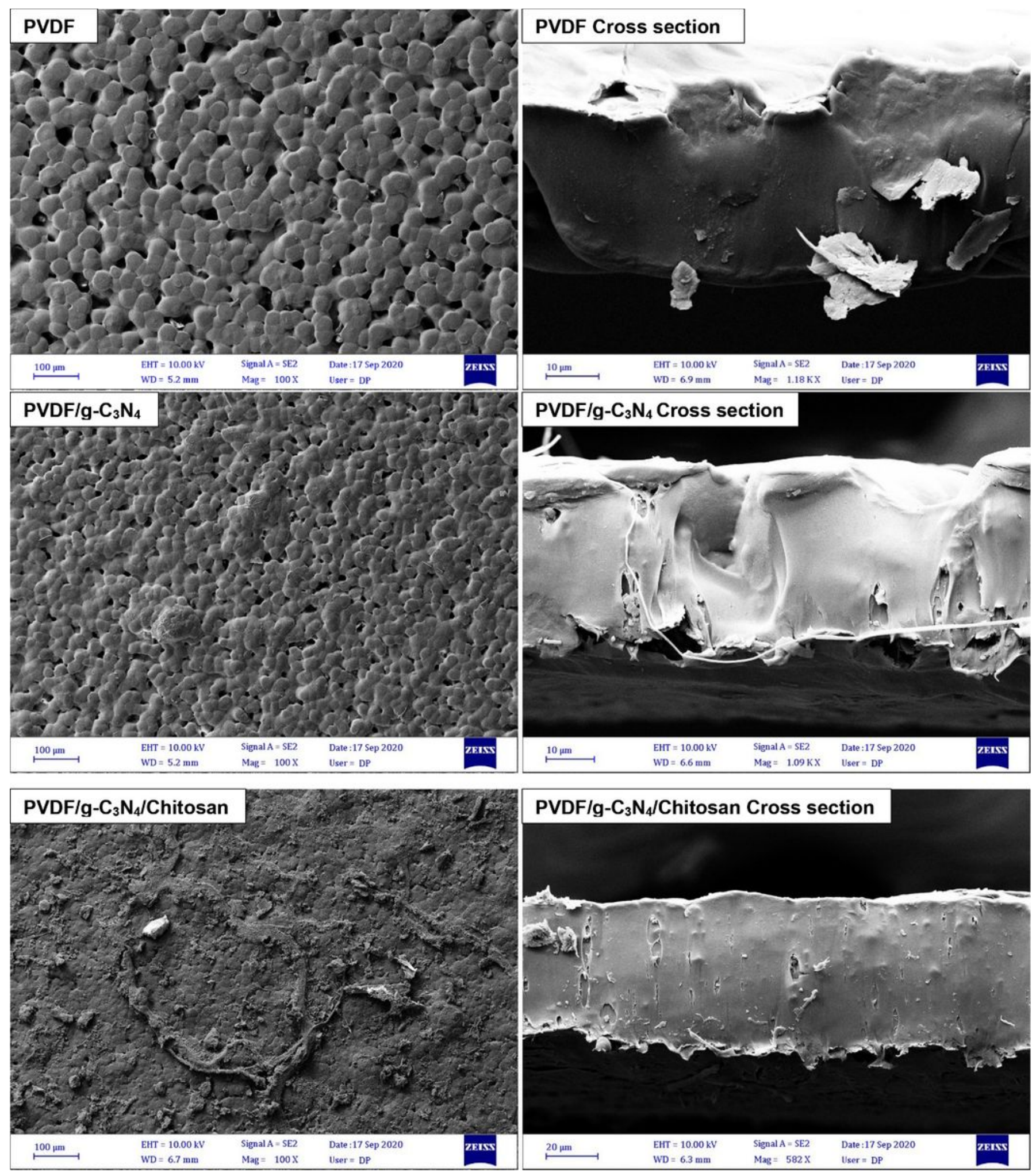

Figure 3

FESEM images of prepared membranes, surface morphology and cross section 

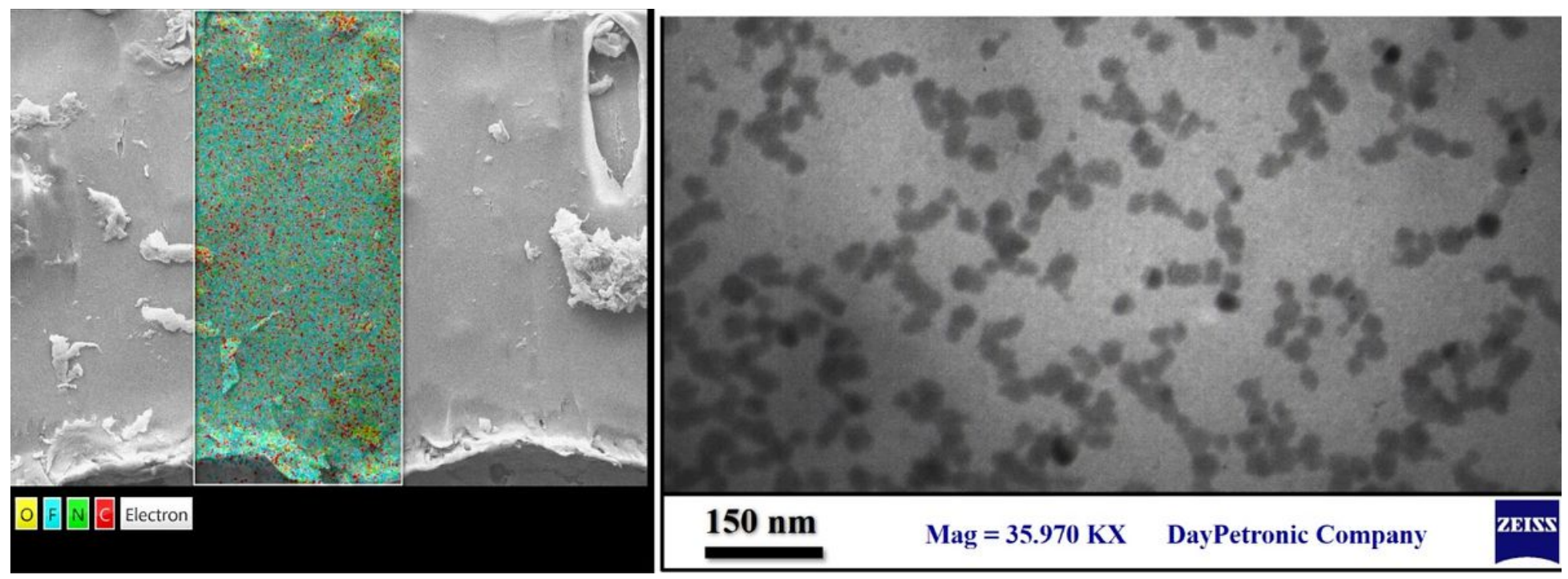

\section{Figure 4}

TEM and EDS mapping of PVDF/g-C3N4/Chitosan membrane
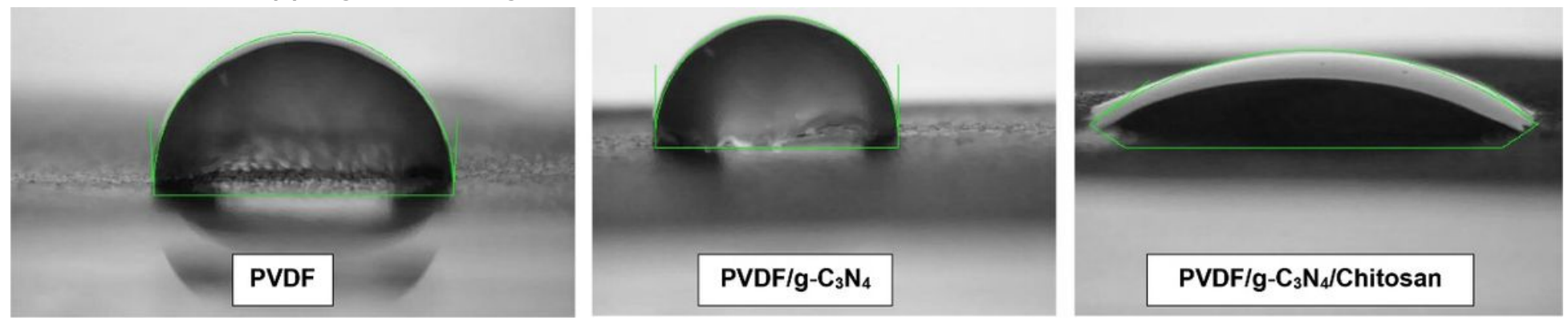

Figure 5

Water contact angle of prepared membranes

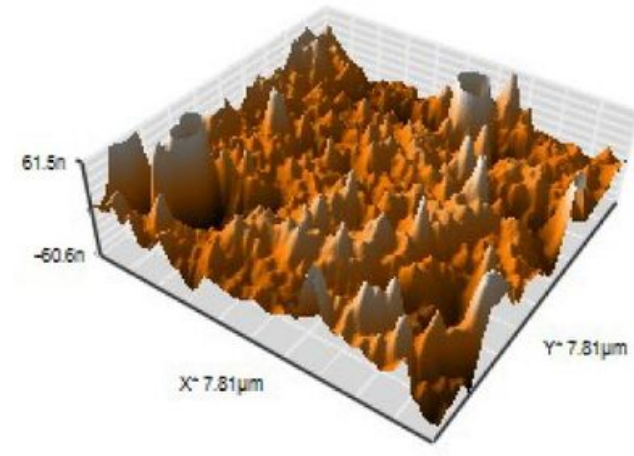

PVDF

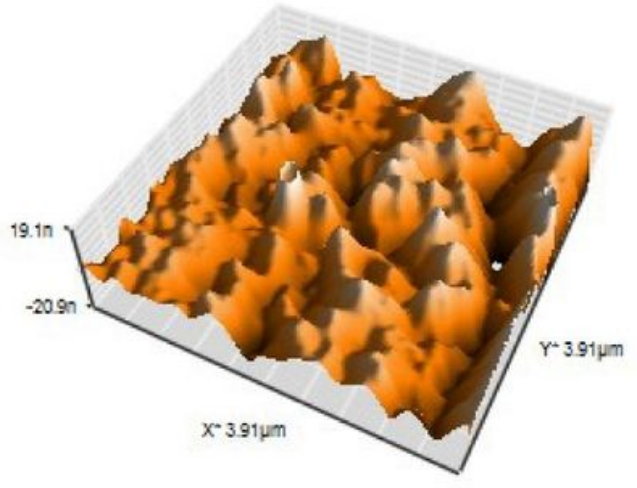

$\mathrm{PVDF} / \mathrm{g}-\mathrm{C}_{3} \mathrm{~N}_{4}$

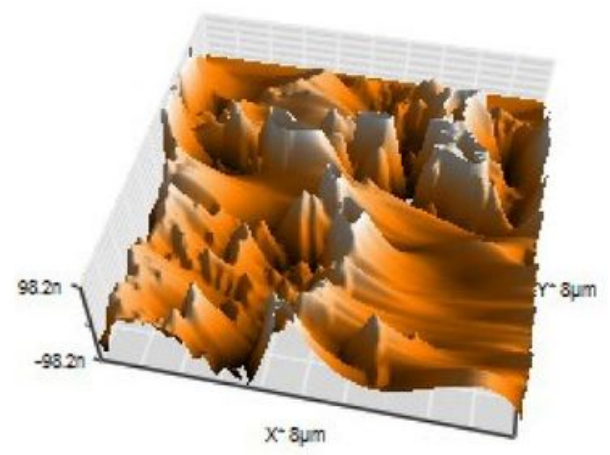

$\mathrm{PVDF} / \mathrm{g}-\mathrm{C}_{3} \mathrm{~N}_{4} /$ Chitosan

Figure 6

AFM images of PVDF, PVDF/g-C3N4 and PVDF/g-C3N4/Chitosan membranes 


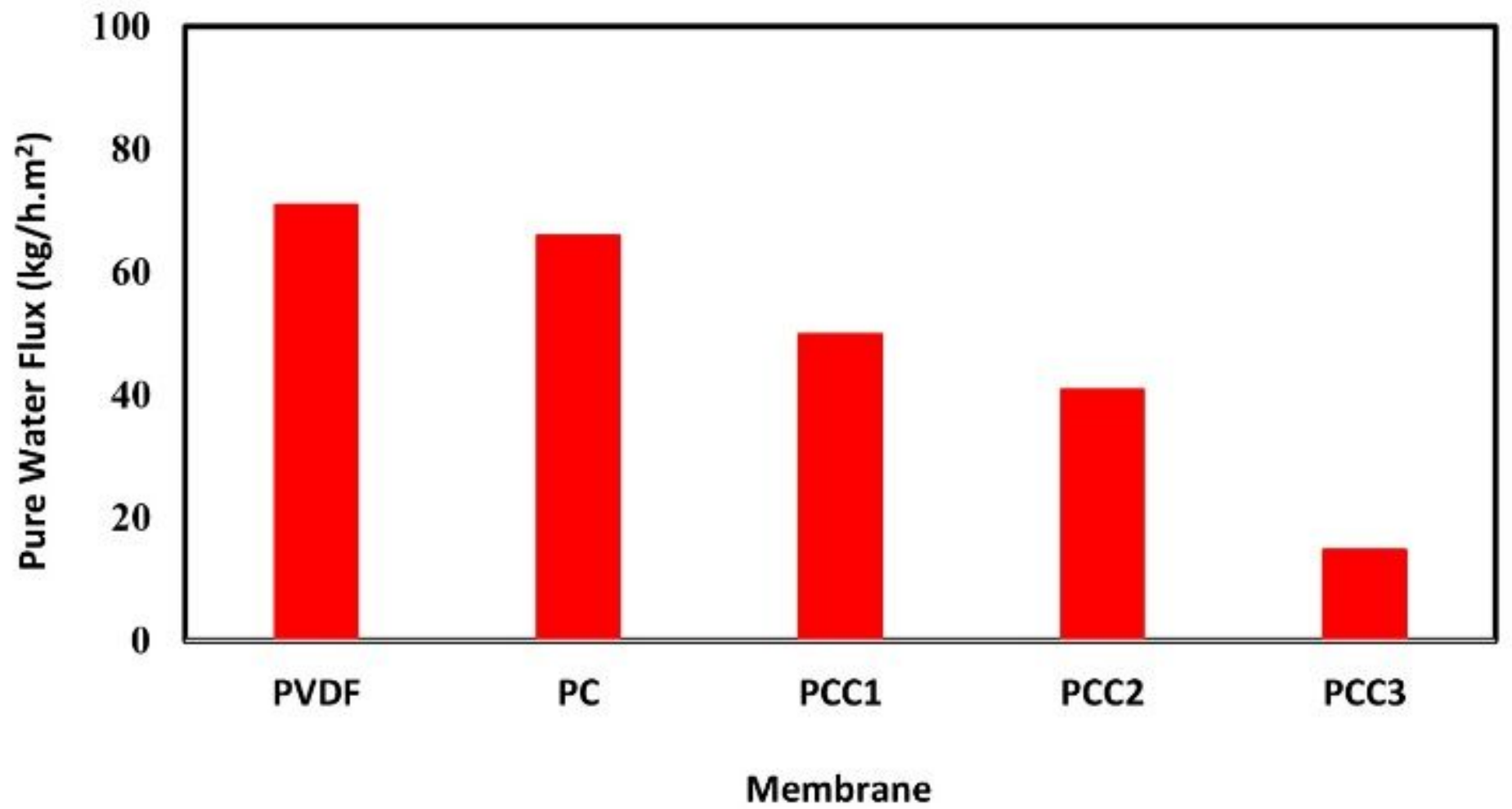

Figure 7

Pure water flux of PVDF, PC, PCC1, PCC2 and PCC3 membranes

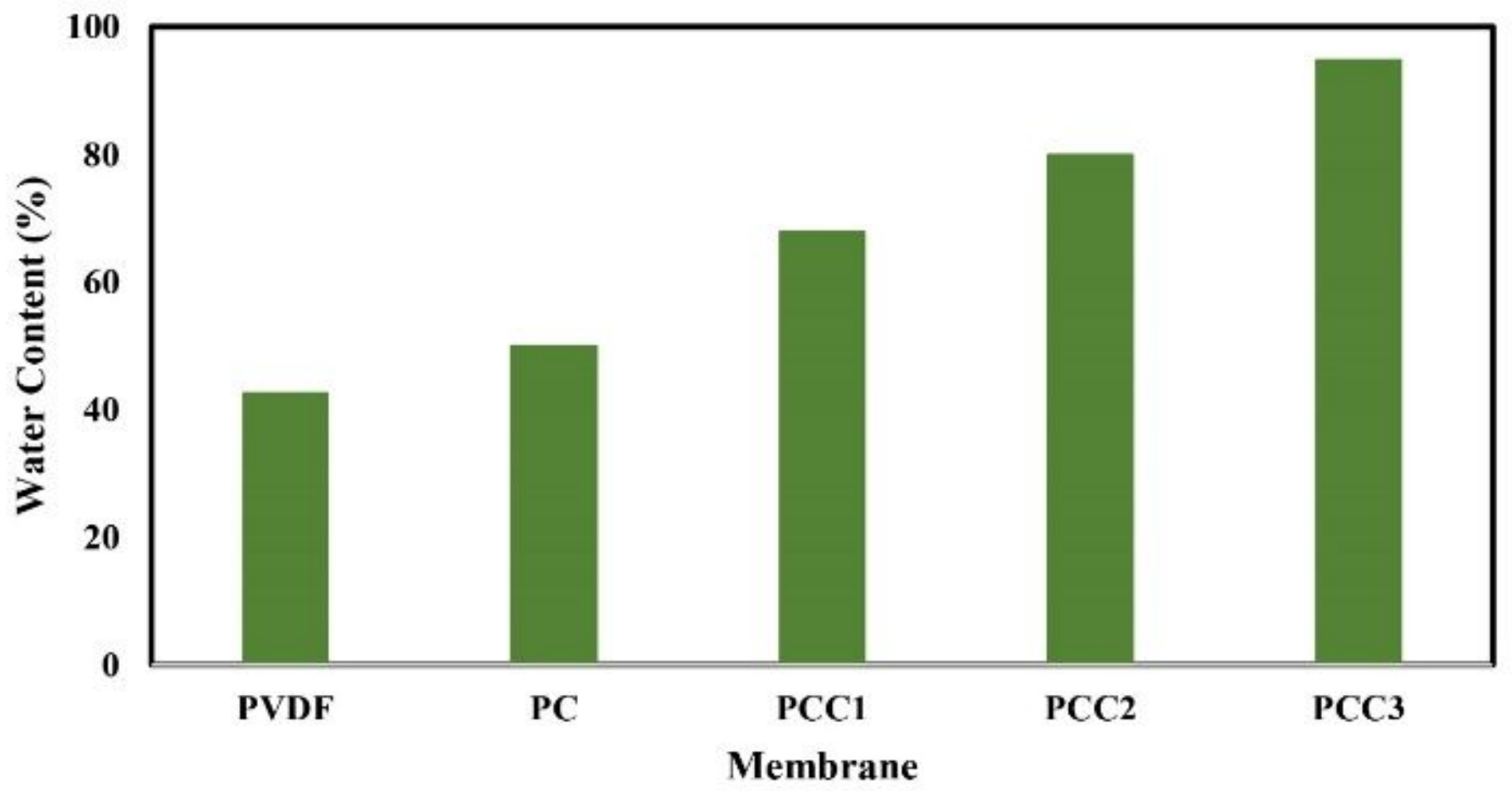

Figure 8 


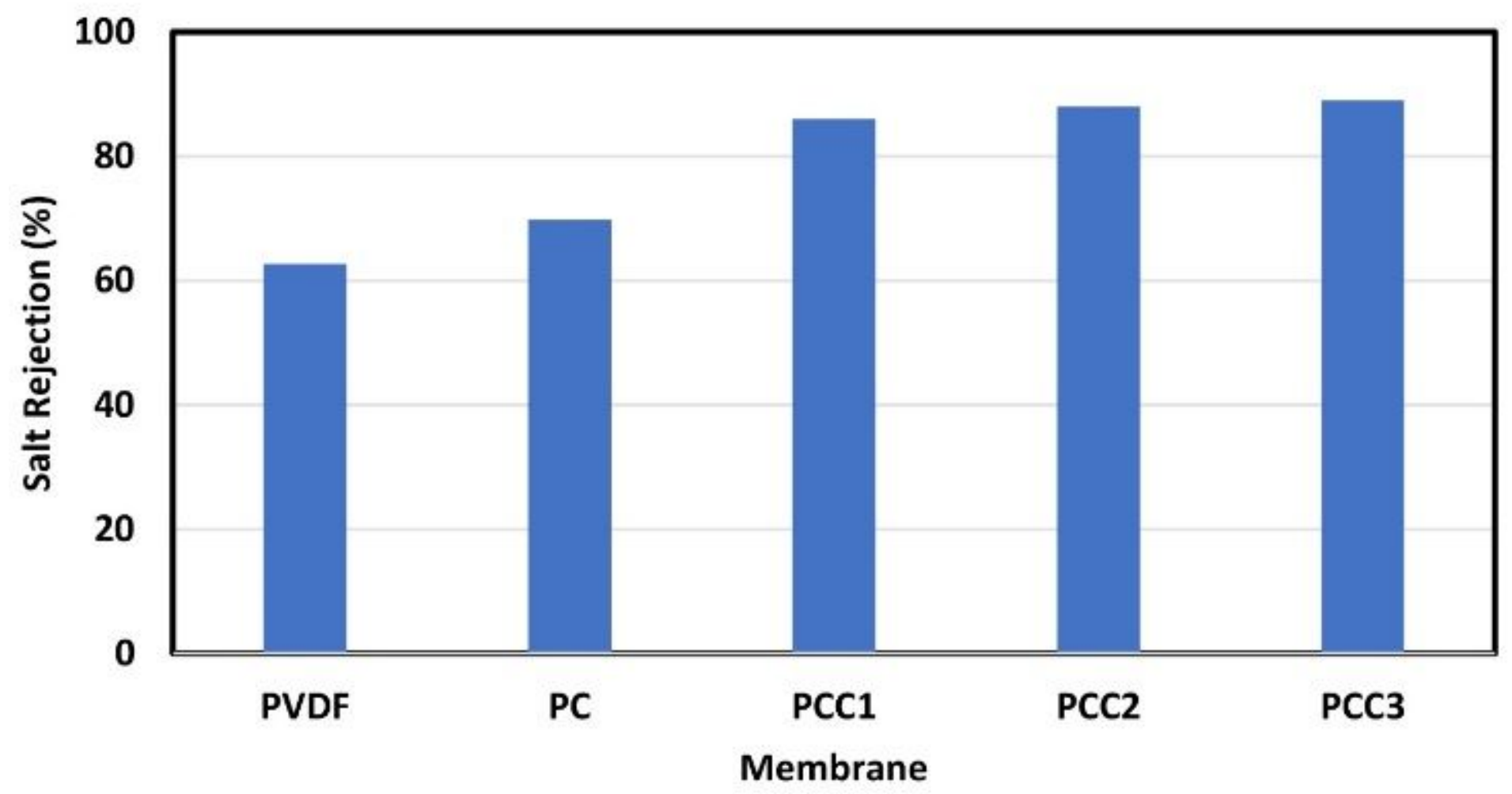

Figure 9

Salt rejection of PVDF, PC, PCC1,PCC2 and PCC membranes
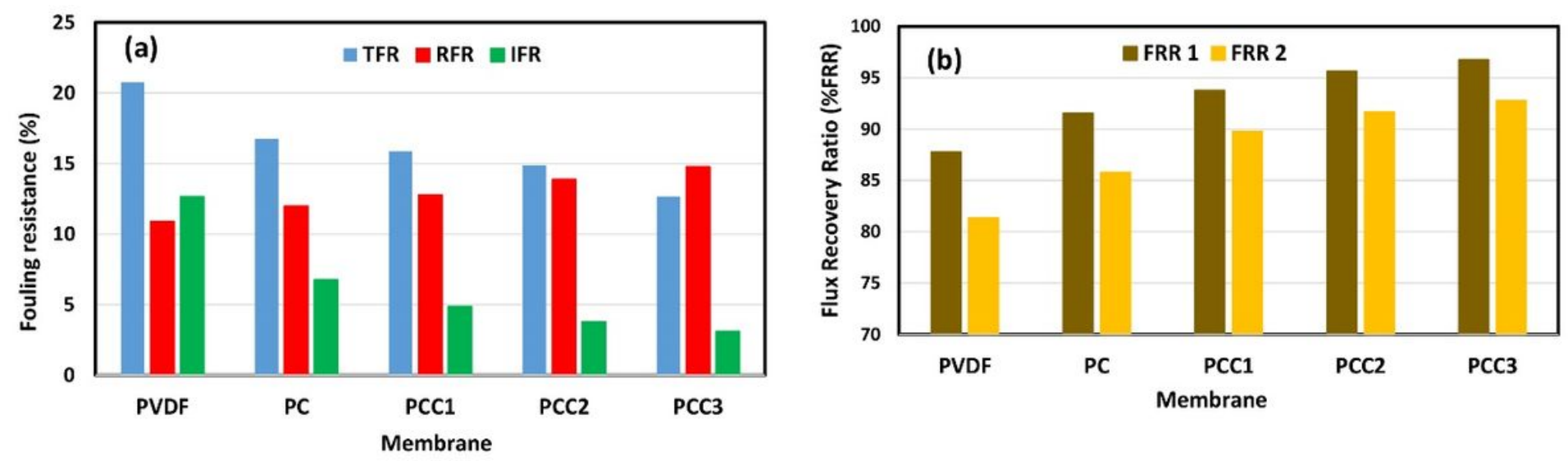

Figure 10

a) Antifouling property of membranes, b) Flux recovery ratio of membranes during 2 cycles of DB14 rejection 

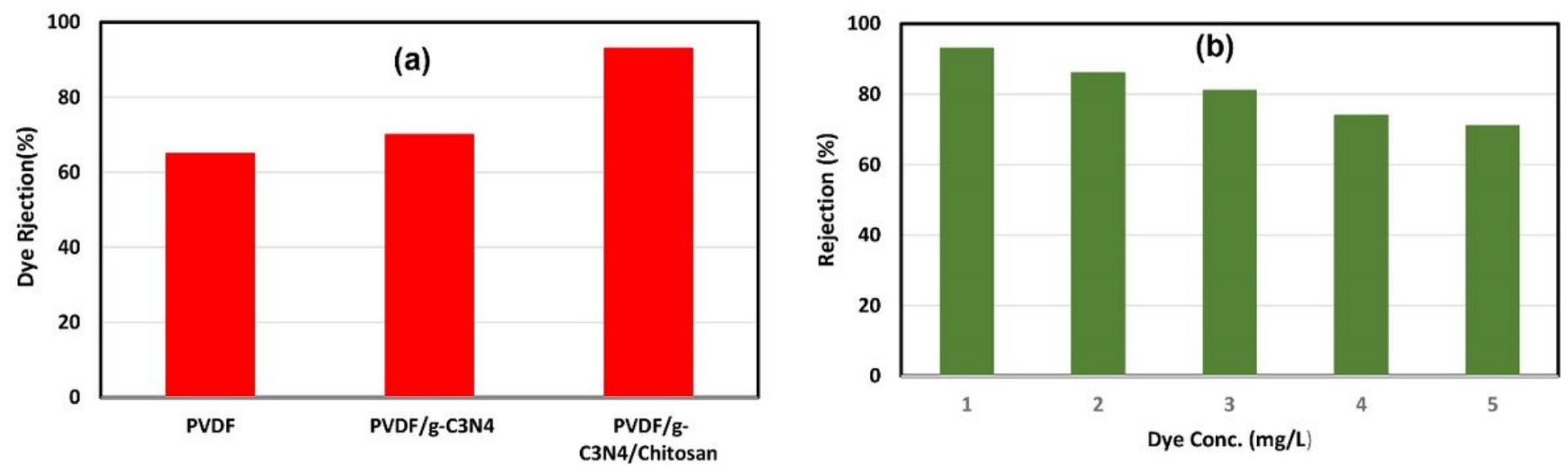

Figure 11

Rejection of DB14 (a) by prepared membranes (DB14 conc. $=2 \mathrm{mg} / \mathrm{L}$ ), b) at different concentrations by $\mathrm{PVDF} / \mathrm{g}-\mathrm{C} 3 \mathrm{~N} 4 /$ Chitosan membrane 